\title{
Neutral Loss of Phosphopeptides upon Electron Capture Dissociation with a Hot Dispenser Cathode
}

\author{
Sunyoung Lee, Seonghee Ahn, ${ }^{\dagger}$ Yong-hyeon Yim, ${ }^{\dagger}$ Byeongjoo Kim, ${ }^{\dagger}$ Hun-Young So,${ }^{\dagger}$ and Han Bin $\mathrm{Oh}^{\star}$ \\ Department of Chemistry and Interdisciplinary Program of Integrated Biotechnologu, Sogang Lniversitw, Seoul 121-742, Korea \\ E-mail: hambinohasogang.ac.kr \\ ${ }^{\dagger}$ Korea Research Institute of Standards and Science, Daejeon 305-340, Korea \\ Received March 2, 2007
}

Key Words : Phosphopeptide. Fourier transform mass spectrometry (FTMS). Electron capture dissociation. Neutral loss. Hot dispenser cathode

Characterizing post-translational modifications (PTMs) in proteins bears a special intportance in biology and also poses a daunting technical challenge in mass spectrometry. ${ }^{10}$ Among many PTMs, intensive attention has been paid to the determination of phosphorylation sites. A variety of approaches have been applied to tackle this challenge. ${ }^{3 \cdot 16}$ The general approach currently employed is to monitor the neutral loss that arises from the detacliment of a specific PTM group upon activation of precursor ions. ${ }^{1 \hat{2} \cdot 14}$ In the case of phosphorylation, the subject of this paper, the two ionpeaks in MS/MS spectra that show a mass difference of 80 $\left(-\mathrm{HPO}_{3}\right)$ or $98\left(-\mathrm{H}_{3} \mathrm{PO}_{4}\right)$ Da from the intact ions indicate that the precursor peptide/protein is very likely to contain a phosphorylated amino-acid residue. Once the potential existence of a PTM group is determined, then the PTM candidate precursor ions are subjected to subsequent MS/ MS investigation to identify the original peptide and the phosphorylation site. Facile loss of a phosphate group upon thermal activation is known to occur through $\beta$-elinination. ${ }^{14.15}$ Although the neutral loss is very useful in determining the presence of phosphory lated PTMs. it often poses difficulty in localizing the phosphorylated sites since the phosphate-detached precursor ions often show a MS/MS pattern very similar to that of non-phosphorylated precursor ions.

On the other hand. electron capture dissociation (ECD) or electron transfer dissociation (ETD), which are types of nonthermal activation MS/MS. carry a strong possibility of retaining a labile phosphate moiety during the backbone dissociation. ${ }^{2-113}$ Furthermore, these niethods generally give rise to a more extensive backbone coverage than the other MS/MS methods based on energetic heating (collisions or multiphoton absorptions). Even with this obvious merit. ECD/ETD shows a weakness when coupled with liquid chromatography. Since the labile phosphate moiety is usually retained in ECD applications, this method cannot provide an alerting signal of a 80 or $98 \mathrm{Da}$ loss indicating the presence of a phosphory lated PTM.
In order to overcome this weakness of ECD/ETD. the following altentative approach has been developed. a socalled 'neutral loss aided ECD/ETD' ${ }^{89}$ In the survey scan. an energetic MS/MS is employed in order to detect the loss of a phosphorylated PTM. When the loss is detected, ECD/ ETD is subsequently applied to the precursor ions in order to identify and localize the phosphorylated group. This approach has been demonstrated to be very powerful when the analy sis is focused on the characterization of PTMs. However, a more desirable approach would be one that can provide an alerting neutral loss signal and backbone cleavage information simultaneously.

Recently, we have noticed that when a hot dispenser cathode employed for electron emission was located just belind the back trap-plate of an ion cyclotron resonance (ICR) cell. the molecular ions in the ICR cell were heated to high temperatures. ${ }^{17}$ The rise of ion internal temperatures was due to the absorption of blackbody radiation from the hot surface of the dispenser cathode. In the case of $8.6 \mathrm{kDa}$ ubiquitin ions, for example. it was found that the effective internal temperature of the ions was approximately $125^{\circ} \mathrm{C}$ under the given experimental conditions. ${ }^{17}$ This temperature is presumably high enough to cause the loss of a phosphate moiety. If our ECD configuration can induce a substantial neutral loss as well as backbone cleavage. this method would be the most desirable for characterizing phosphorylated PTMs. Based on this expectation, we perfonmed preliminary ECD experiments on two phosphopeptides. one phosphoserine and one phosphotyrosine peptide, with the cathode configuration mentioned above. In preliminary experiments. we obtained the promising results presented below. More rigorous and systematic investigations are still underway and will be presented in the near future.

\section{Experimental Section}

The experimental setup employed in the present study is identical to that described in previous studies. ${ }^{17.19}$ Thus, only 
a brief description will be given here. Experiments were performed on a commercial 12 Tesla electrospray ionization Fourier transform mass spectrometer (ESI-FTMS. Ionspec Inc.. Lake Forest, CA, USA) with ECD capability. A sample was prepared at a concentration of $20 \mathrm{mM}$ in a $49: 49: 2$ $(\mathrm{v} / \mathrm{H} / \mathrm{v})$ water methanolacetic acid solution, and was sprayed through a Z-spray source at a flow rate of $0.5-1 \mu \mathrm{L} / \mathrm{min}$ using a syringe pump (Harvard Apparatus 22, Holliston. MA. USA). The emitter was operated in positive mode at a potential of $-3 \mathrm{kV}$ between the emitter and the sampling cone. Isolation of the molecular ions of interest was achieved using a sungle stored waveform inverse Fourier-transform (SWIFT) procedure ${ }^{18}$ In the ECD experinent. the isolated precursor lons were irradiated for $1.0 \mathrm{~s}$ with electrons generated on the dispenser cathode. A 3.4-1mm-diameter dispenser cathode (Heatwave Labs, Watsonville. CA,USA) was mounted on a marcor insulator block located just behind (less than $\mathrm{I} \mathrm{cm}$ ) the trap plate of the ICR cell. The electron kinetic energy was $1.0 \mathrm{eV}$. Data analysis was perfonned using PeakHuuter 1.1 beta provided by Ionspec Inc

\section{Results and Discussion}

The two phosphorylated peptides enployed were TSTEPQ[pS]QPGENL $\left(\mathrm{M}_{\mathrm{r}}=1466.59\right)$ and TSTEPQ[pY]QPGENL $\left(\mathrm{M}_{\mathrm{r}}=1542.62\right)$. The latter phosphotyrosine peptide is the carboxyl terminus of $\mathrm{pp} 60^{c-s c c}$, the product of the $c-s r c$ protooncogene. phosphorylated at Tyr-527, ${ }^{21}$ This peptide fragment is known to play an important role in several cellular activities through the regulation of kinase activity by binding intramolecularly or intermolecularly to the $\mathrm{SH} 2$ domain of the pp60 ${ }^{\mathrm{css}} \mathrm{sc}$ protein. The phosphotyrosme peptide was purchased from Bachem (Seoul, Korea) and was used without further punfication. The phosphoserme peptide, with phosphosenne substituted for phosphotyrosine. was used to facilitate the direct comparison with the phosphotyrosine peptide. This peptide was customsynthesized (PeptrEX-R48, Peptron Inc.. Daejeon, Korea).

Characterization of phosphoserme proteins/peptides is important since phosphorylation at serine residues is known to be responsible for $90 \%$ of phosphorylation PTMs. Thus. the first ECD experiments were performed for doublyprotonated phosphoserine (TSTEPQ[pS]QPGENL) peptide ions prepared by ESI. The product-1on mass spectrum and its enlarged partial mass spectra are shown in Figure 1. It is notable that $100 \%$ sequence coverage was achieved, which is in accord with previous studies. ${ }^{+.6}$ Typical ECD products of $c$ and $z^{*}$ ions were mainly responsible for the full sequence coverage.

A close look at the spectra reveals that loss of $-\mathrm{H}_{3} \mathrm{PO}_{4}$ or $-\mathrm{HPO}_{3}$ extensively occurred $\mathrm{in}$ both the precursor and the product ions. As shown in Figure 1. detachments of a phosphate molety arise from singly-protonated precursor ions. causing the peaks at $m: 1370.68$ and 1388.60 . respectively. Furthermore, neutral loss is also found to occur in the $c$ and $z \bullet$ product ions. For example, the following ion peaks represent the products with the phosplate molety detached from their backbone: $\boldsymbol{a}_{12.13}, \boldsymbol{b}_{7.8}, \boldsymbol{b}_{11} . c_{11.12}$. and

(a)

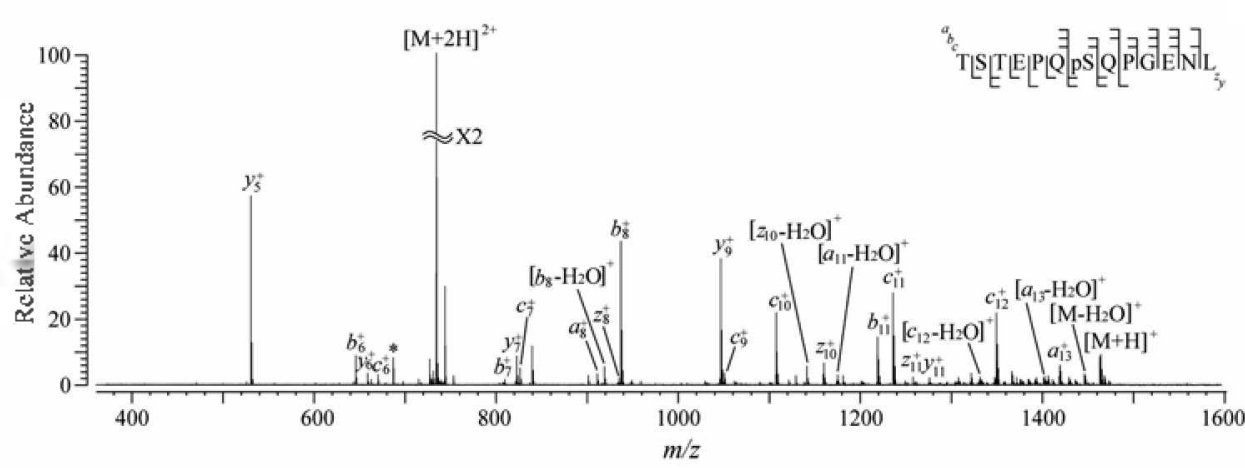

(b)
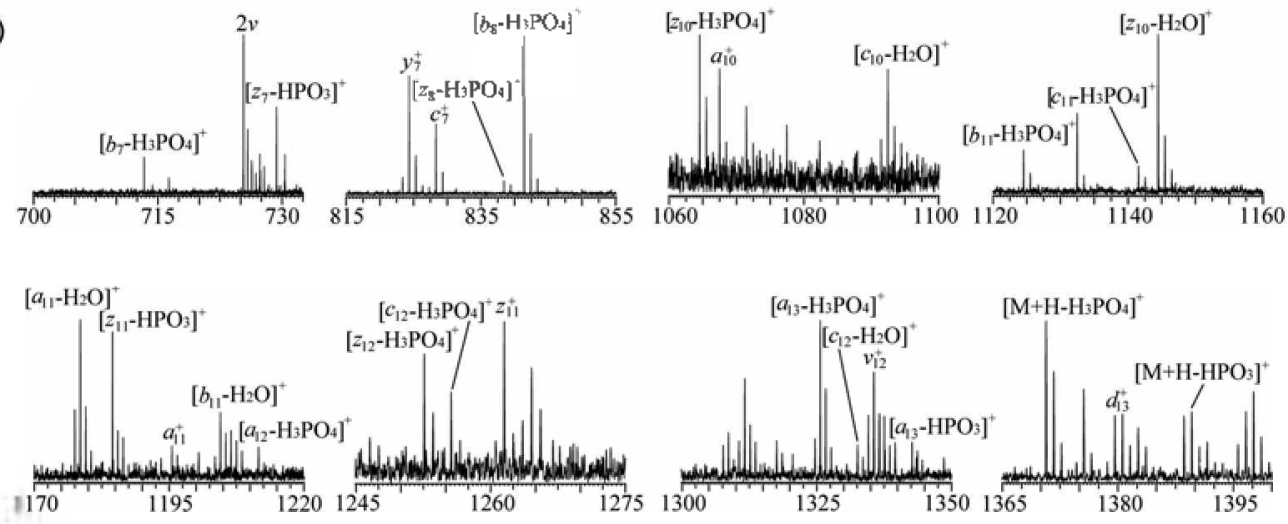

Figure 1. ECD MS/MS spectra tor the doubly charged phosphoserine peptide ions: (a) the overall spectrum and (b) enlarged partial spectra showing a phosphate loss. 
(a)

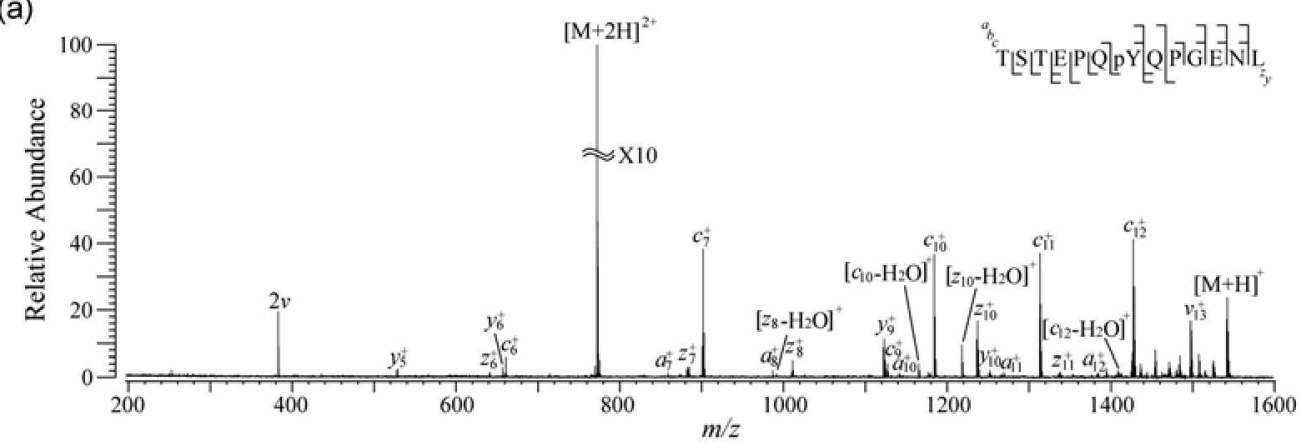

(b)

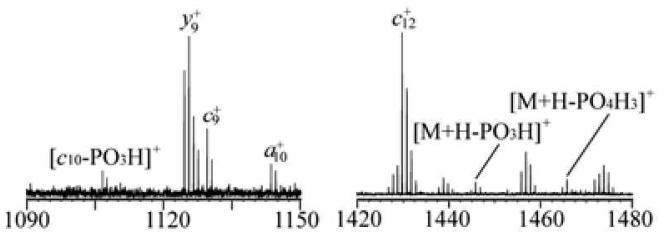

Figure 2. ECD MS/MS spectra for the doubly charged phosphotyrosine peptide ions; (a) the overall spectrum and (b) enlarged partial spectra showing a phosphate loss.

27.8.113-12. In general, the peaks arising from a neutral loss are of low abundance compared to the intact $c$ and $z$. product ions. From the observed spectrum only. it is difficult to determine whether or not the dissociation of the phosphate moiety occurred prior to the ECD backbone dissociation. However. judging from the low abundance of $[\mathrm{M}+\mathrm{H}-\text { phosphate }]^{+}$ions. the detachment presumably occurred after the backbone cleavage. Otherwise. the abundance of $[\mathrm{M}+\mathrm{H} \text { - phosphate }]^{+}$ion peaks would be much higher. Further scrutiny of future double-resonance experiments is expected to reveal the sequence of these two occurrences. ${ }^{2 \geq}$

Loss of a phosphate group in ECD MS is an unexpected phenomenon. In ECD, it has been well established that a labile phosphate group is generally retained during ECD backbone cleavages. ${ }^{-11}$ For example, the Zubarev group did not observe any loss of $\mathrm{H}_{3} \mathrm{PO}_{4}$ or $\mathrm{HPO}_{3}$ from intact peptide ions or fragment ions in their ECD of phosphotyrosinecontaining peptides. ${ }^{6}$ The unexpected loss is likely to be due to the large amount of blackbody radiation from the hot dispenser cathode located just behind the back trap-plate of the ICR cell. In our recent experiments. we observed that the effective internal temperature of $8.6 \mathrm{kDa}$ ubiquitin cations is very high $\left(>100^{\circ} \mathrm{C}\right.$ ) while exposed to the hot dispenser cathode. ${ }^{17}$ In contrast to the other groups who have a dispenser cathode located farther away from the ICR cell. our cathode is located very close to the ICR cell. In our experimental configuration. the trapped molecular ions are likely to be highly activated thermally so as to lose the labile phosphate group. The themal activation in our conditions is further supported by the observation of $b$-type product ions in Figure 1: see $b_{6}{ }^{-}, b_{7}{ }^{+}, b_{8}{ }^{+}$and $b_{11}{ }^{+}$. In the case of $b_{7}^{-}, b_{8}{ }^{+}$ and $b_{11}{ }^{-}$. even neutral loss product-ion peaks, $\left[b_{\mathrm{n}}-\right.$ phosphate group $]^{-}$, were observed

The neutral loss of a phosphate group in ECD was also found to occur in the case of a phosphotyrosine peptide
(Figure 2) even though phosphotyrosine peptides are generally known to be less prone to phosphate group loss, even in CAD (collisionally activated dissociation) conditions. ${ }^{15}$ This propensity is well represented in the spectrum for the phosphotyrosine peptide, where the loss was not as ubiquitous as in the phosphoserine peptide (Figure 1).

To summarize, in our ECD experimental configuration in which a hot dispenser cathode was located very close to the ICR cell. a labile phosphate group was observed to dissociate from both the molecular and product ions, as a minor product pathway. Since the typical ECD backbone cleavages leading to $c, z *$ ions are still a major product channel, the neutral loss did not hinder localization of the PTM. In chromatographic experiments, the neutral loss of -80 or -98 Da strongly indicates that there is a potential phosphoryl-

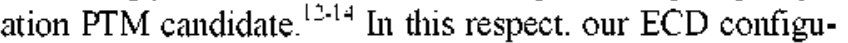
ration is advantageous in achieving the neutral loss and backbone cleavages simultaneously. In ECD applications. this can also be similarly achieved by applying a combination of ECD and other thermal activation methods such as CAD and IRMPD ${ }^{45,7}$ However, with our configuration, an extra activation method was not required. Our results clearly indicate that our experimental configuration using a hot dispenser cathode close to the ICR cell is a powerful tool for identification of phosphopeptides. Currently more experiments with a variety of phosphopeptides are underway in order to verify our preliminary results.

Acknowledgments. The authors are grateful to Changhun Park. Kun Cho. Soojin Park. Sunghỵun Yu. Donghyun Kang. and Hyuntae Jung for their help in experiments and discussions. This work was supported by Seoul Research and Business Development Program (10816). HBO is also indebted to a grant provided by the Korea Research Institute of Standards and Science by the Ministry of Science and Teclunology from the Basic Science Research Funds. 


\section{References}

1. Fridriksson. E. K.: Beavil. A.: Holowka. D.: Gould. H. J.: Baird. B.: McLaffert: F. W. Biochemishn 2000, 39,3369.

2. Ge, Y: Lawhorn. B. G.: ElNaggar. M.: Strauss, E.: Park. I.H.: Beglev. T. P.: McLafferts. F. W. J. Am. Chem. Soc. 2002, 124.672.

3. Sze. S. K.: Ge. Y: Oh. H. B.: McLafterty. F. W. Proc. Nail Acad Sci. $l S A$ 2002. 99.1774

4. Shi. S. D.-H.: Hemling. M. E.: Carr. S. A.: Hom. D. M.: Lindh. I.: MeLafferty, F. W. Anal. Chem. 2001, 73. 19

5. Chalmers, M. J.: Hakansson, K.: Johnson, R.: Smith, R.: Shen, I.: Emmett, M. R: Marshall, A. G. Proteonics 2004. 4.970.

6. Stensballel. A.: Jensen. O. N.: Olsen. J. V.: Haselmann. K. F.: Zubarev. R. A. Rapid Conmunt. Afass Spectrom. 2000. It. 1793

7. Häkansson, K: Chalmers, M. J.: Quinn, J. P.: MeFarland. M. A.: Hendrickson. C. L.: Marshall. A. G. Anal them. 2003. 75. 3256

8. Coon, J. J: Shabanowitz, J: Hunt D. F: Syka, J. E. P. J. Am. Soc. Mass Spectrom. 2005. 16.880

9. Chi. A.: Huttenhower. C.: Geer. L. Y:: Coon. J. J.: Syka. J. E. P.: Bai. D. L.: Shabanowitz. J.: Burke. D. J.: Trovanskaya. O. G.: Hunt D. F. Proc. Kail. Acad Sci. LS. 2007. 104. 2193.

10. Jebanathirajah. I. A.: Pittnin. J. L.: Thomson. B. A.: Budnik. B. A.: Kaur. P.: Rape, M.: Kirscluter. M.: Costello, C. E.: O'Connor,
P. B. J. Am. Soc. Mass Spectront. 2005. 16. 1985.

11. Stevens. S. M.. Tr.: Chung. A. Y: Chow: M. C.: McClung. S. H.: Strachan. C. N.: Harmon. A. C.: Denslow: N. D.: Prokai. L. Rapid Conmun. Mass Spectrom. 2005. 19,2157.

12. Carr. S. A.: Huddleston. M. J.; Annan, R. S. And. Biochem. 1996. 239. 180.

13. Hoffert. T. D.: Pisithunn. T.: Wang. G.: Shen. R.-F.: Knepper. M. A Proc. Natl Acad Sci. USA 2006. 103.7159.

14. Antrant. R. S.: Carr. S. A. Anal Chem. 1996. 68.3413.

15. DeGnore. J. P. Qin. J. J. Am. Soc. Mass Spectrom. 1998, 9, 1175.

16. Crowe. M. C.: Brodbelt, J. S. J. Am. Soc. Mass Spectrom 2004. 15. 1581 .

17. Yim. Y. H.: Kimn. B.: Ahn. S.: So. H.-Y.: Lee. S.: Oh. H. B. Rapid Conmtim. Mass Spectront. 2006. 20. 1918.

18. Yu. S.: Cho. K.: Kim. Y. H.: Park. S. T.: Kiml. T. D.: Oh. H. B. Bull. Korean Chem. Soc. 2006. 27, 793.

19. Han. S. Y.: Lee, S. Y.: Oh, H. B. Bull Konan Chem Soc, 2005. 26. 740 .

20. Marshall. A. G.: Wang. I. C. L.: Ricca. T. L. J. Am. Chem. Soc. 1985. 107. 7893.

21. Roussel. R. R.: Brodeur. S. R.: Shalloway. D.: Laudano. A. P. Proc. Nail Acad Sci. USA 1991,88. 10696.

22. Lin. C.: Coumover. J. J.: O'Connor. P. B. J. Am. Soc. Mass Spectrom. 2006. 17, 1605 . 